\title{
Gene expression profiling of 49 human tumor xenografts from in vitro culture through multiple in vivo passages - strategies for data mining in support of therapeutic studies
}

\author{
Melinda G Hollingshead ${ }^{1 *}$, Luke H Stockwin², Sergio Y Alcoser ${ }^{3}$, Dianne L Newton², Benjamin C Orsburn ${ }^{4}$, \\ Carrie A Bonomi ${ }^{2}$, Suzanne D Borgel ${ }^{2}$, Raymond Divelbiss ${ }^{2}$, Kelly M Dougherty ${ }^{2}$, Elizabeth J Hager ${ }^{3}$, \\ Susan L Holbeck ${ }^{5}$, Gurmeet Kaur ${ }^{6}$, David J Kimmel², Mark W Kunkel ${ }^{5}$, Angelena Millione², \\ Michael E Mullendore ${ }^{2}$, Howard Stotler ${ }^{2}$ and Jerry Collins ${ }^{7}$
}

\begin{abstract}
Background: Development of cancer therapeutics partially depends upon selection of appropriate animal models. Therefore, improvements to model selection are beneficial.

Results: Forty-nine human tumor xenografts at in vivo passages 1,4 and 10 were subjected to CDNA microarray analysis yielding a dataset of 823 Affymetrix HG-U133 Plus 2.0 arrays. To illustrate mining strategies supporting therapeutic studies, transcript expression was determined: 1) relative to other models, 2) with successive in vivo passage, and 3) during the in vitro to in vivo transition. Ranking models according to relative transcript expression in vivo has the potential to improve initial model selection. For example, combining p53 tumor expression data with mutational status could guide selection of tumors for therapeutic studies of agents where p53 status purportedly affects efficacy (e.g., MK-1775). The utility of monitoring changes in gene expression with extended in vivo tumor passages was illustrated by focused studies of drug resistance mediators and receptor tyrosine kinases. Noteworthy observations included a significant decline in HCT-15 colon xenograft ABCB1 transporter expression and increased expression of the kinase KIT in A549 with serial passage. These trends predict sensitivity to agents such as paclitaxel (ABCB1 substrate) and imatinib (c-KIT inhibitor) would be altered with extended passage. Given that gene expression results indicated some models undergo profound changes with in vivo passage, a general metric of stability was generated so models could be ranked accordingly. Lastly, changes occurring during transition from in vitro to in vivo growth may have important consequences for therapeutic studies since targets identified in vitro could be over- or under-represented when tumor cells adapt to in vivo growth. A comprehensive list of mouse transcripts capable of cross-hybridizing with human probe sets on the HG-U133 Plus 2.0 array was generated. Removal of the murine artifacts followed by pairwise analysis of in vitro cells with respective passage 1 xenografts and GO analysis illustrates the complex interplay that each model has with the host microenvironment.
\end{abstract}

Conclusions: This study provides strategies to aid selection of xenograft models for therapeutic studies. These data highlight the dynamic nature of xenograft models and emphasize the importance of maintaining passage consistency throughout experiments.

Keywords: Xenograft models, Affymetrix HG-U133 Plus 2.0 array, cDNA microarray, NCI-60 cell line screen, Transcriptomic stability, Transcriptomic expression, in vitro to in vivo transition

\footnotetext{
* Correspondence: hollingm@mail.nih.gov

1 Biological Testing Branch, National Cancer Institute at Frederick, 1050 Boyles

Street, Building 1043, Room 11, Frederick, MD 21702, USA

Full list of author information is available at the end of the article
} 


\section{Background}

Xenograft models remain a cornerstone technology in the development of anti-cancer agents [1]. The ability of immunocompromised rodents to support the growth of human tumors provides an invaluable transition between in vitro testing, pre-clinical development and clinical trials. For decades, data from xenograft models has informed development decisions with respect to dosing schedules, pharmacokinetics/pharmacodynamics (PK/PD) and potential toxicities. Yet several challenges remain, including understanding the extent to which well-characterized xenograft models replicate the biology and growth characteristics of patient disease. Furthermore, with the paradigm shift towards agents with specific molecular targets and personalized medicine, a comprehensive molecular profile for xenograft models may be essential for successful in vivo evaluation. To this end, considerable resources are being applied to the generation of novel xenograft models combined with molecular profiling of existing models [2].

Within the Developmental Therapeutics Program (DTP) of the National Cancer Institute, the primary in vitro assay used to detect potential anti-cancer activity is the NCI-60 cell line screen. To date, this panel of human tumor lines has been used to evaluate almost one hundred thousand pure compounds and approximately fifty thousand natural product extracts. Many of these cell lines will grow as subcutaneous xenografts, thus cell lines sensitive to an agent in vitro were often subjected to further analyses in xenografts derived from those cell lines. The NCI-60 panel has been extensively molecularly characterized, with data available for gene expression, DNA variation (mutation and SNPs), protein expression, DNA methylation, microRNA expression and metabolomics (http://dtp. cancer.gov/mtargets/mt_index.html) [3-9]. The COMPARE algorithm (http://dtp.nci.nih.gov/docs/compare/ compare.html) allows investigators to correlate NCI-60 drug activity profiles with all other open agents in the database and with molecular characteristics of the cells [10]. While the in vitro grown cells have been characterized, the corresponding subcutaneous xenografts had not. However, other studies have succeeded in molecular profiling of other xenografts $[2,11,12]$. These predominantly cDNA and tissue-array based studies lack the potential for retrospective cross-platform analysis that underscores the NCI-60 cell line set.

The MicroXeno Project was initiated to generate genome-wide cDNA microarray data for all subcutaneous xenograft models currently used within the DTP. Comprehensive transcriptomic analysis will help address questions such as: Can expression of molecular target[s] help inform model selection for a given agent or target, or to what extent and by what manner do specific cell line tumors adapt during prolonged growth in vivo? The work presented here provides a reference dataset that can be used to confirm the genetic characteristics and stability of models going forward. This ongoing project will ultimately encompass over 100 models, with data from cell lines and successive xenograft passages. The panel includes tumor cell lines from diverse histological origins including leukemia/ lymphoma, non-small cell lung, colon, CNS, melanoma, ovarian, renal, prostate, liver, gastric, head and neck, pancreatic, and breast cancer. It also includes, but is not limited to, many of the cell lines in the NCI-60 panel (http://dtp. cancer.gov/docs/misc/common_files/cell_list.html).

Here we describe the procedures and quality control criteria used to derive MicroXeno release 1.0. The study utilizes Affymetrix HG-U133 Plus 2.0 arrays, capable of identifying more that 30,000 human transcripts from $>54,000$ probe sets [13]. The current release encompasses 49 experiments with each consisting of data from the originating cell lines and the resulting xenografts at passages 1, 4 and 10 (P1, P4, P10). In addition, we detail several approaches to utilize the data to predict possible biological outcomes. We propose that this dataset [and subsequent releases] will improve selection and execution of subcutaneous xenograft experiments during the evaluation of cancer therapeutics. As this study is based primarily on lines from the NCI-60 panel, the potential also exists for integration with other NCI-60 datasets (mutational analysis, protein arrays, etc.). Rapid dissemination of this data will also permit the extramural community to perform meta-analyses in support of their own in vivo studies.

\section{Results and discussion}

This study focused on generating pan-genomic cDNA microarray data for diverse xenograft models from the time of initial implantation to the tenth passage using the Affymetrix HG-U133 Plus 2.0 array. Each experiment comprised the originating in vitro cell lines [designated P0] along with tumor samples from in vivo passages 1,4 and 10. For each in vivo passage, five tumors were harvested. The 49 human xenograft experiments contained within this release led to the generation of 844 arrays. Table 1 details the specific cell lines along with tumor types, histology, host strain and any special growth requirements or irregularities.

\section{Microarray data quality control}

Multiple layers of quality control criteria were applied to the dataset. First, the $844 \mathrm{CEL}$ files (including P4 and P10 of SF-268 and SF-539) were visually inspected using DChip (http://www.hsph.harvard.edu/cli/complab/dchip/) to identify arrays with structural defects. Significant physical issues were identified in one MDA-MB-231 T P4 sample, which was removed. Next, .CEL files were uploaded and analyzed en masse using the QC tools contained within 
Table 1 Tumor cell lines, host mice, protocol variances

\begin{tabular}{|c|c|c|c|c|}
\hline Tumor type $^{a}$ & Tumor name & Histology & Mouse strain & Comments \\
\hline \multirow[t]{2}{*}{ Breast } & MCF7 $^{b}$ & Adenocarcinoma & $\mathrm{nu} / \mathrm{nu} \mathrm{NCr}$ & 2 samples $\mathrm{P0}, 4$ samples $\mathrm{P} 1$ \\
\hline & MDA-MB-231 T & Adenocarcinoma, from mouse & $\mathrm{nu} / \mathrm{nu} \mathrm{NCr}$ & 2 samples P0 \\
\hline Cervical & HeLa-Luc & Adenocarcinoma & $\mathrm{nu} / \mathrm{nu} \mathrm{NCr}$ & 2 samples $\mathrm{PO}$ \\
\hline \multirow[t]{3}{*}{ CNS } & SF-268 ${ }^{C}$ & Anaplastic Astrocytoma & NOD.SCID/NCr & 2 samples $\mathrm{P} 0, \mathrm{P} 4$ and $\mathrm{P} 10$ are mouse \\
\hline & SF-539 & Glioblastoma & NOD.SCID/NCr & 2 samples $\mathrm{P} 0, \mathrm{P} 4$ and $\mathrm{P} 10$ are mouse \\
\hline & U251 & Glioblastoma & $\mathrm{nu} / \mathrm{nu} \mathrm{NCr}$ & 2 samples P0 \\
\hline \multirow[t]{7}{*}{ Colon } & COLO 205 & Adenocarcinoma & $\mathrm{nu} / \mathrm{nu} \mathrm{NCr}$ & \\
\hline & HCC-2998 & Carcinoma & $\mathrm{nu} / \mathrm{nu} \mathrm{NCr}$ & \\
\hline & HCT-116 & Carcinoma & $\mathrm{nu} / \mathrm{nu} \mathrm{NCr}$ & \\
\hline & HCT-15 & Adenocarcinoma & $\mathrm{nu} / \mathrm{nu} \mathrm{NCr}$ & \\
\hline & HT-29 & Adenocarcinoma, GR III & $\mathrm{nu} / \mathrm{nu} \mathrm{NCr}$ & \\
\hline & KM12 & Adenocarcinoma & $\mathrm{nu} / \mathrm{nu} \mathrm{NCr}$ & \\
\hline & SW-620 & Adenocarcinoma & $\mathrm{nu} / \mathrm{nu} \mathrm{NCr}$ & \\
\hline Gastric & GTL 16 & Adenocarcinoma & $\mathrm{nu} / \mathrm{nu} \mathrm{NCr}$ & 2 samples P0 \\
\hline Leukemia/ & AS283 & AIDs related Burkitts Lymphoma & $\mathrm{SCID} / \mathrm{NCr}$ & 2 samples P0 \\
\hline \multirow[t]{6}{*}{ Lymphoma } & CA46 & B Lymphocyte Burkitts Lymphoma & $\mathrm{SCID} / \mathrm{NCr}$ & 2 samples $\mathrm{PO}$ \\
\hline & CCRF-CEM & Acute Lymphoblastic Leukemia (T-ALL) & $\mathrm{SCID} / \mathrm{NCr}$ & \\
\hline & $\mathrm{HL}-60(\mathrm{~TB})$ & Promyelocytic Leukemia & $\mathrm{SCID} / \mathrm{NCr}$ & 3 samples P5 substituted for P4; 4 P0 samples \\
\hline & K-562 & Chronic Myelogenous Leukemia & $\mathrm{SCID} / \mathrm{NCr}$ & 5 samples $P 5$ substituted for $P 4,4$ samples $P 10$ \\
\hline & MOLT-4 & Acute Lymphoblastic Leukemia & $\mathrm{SCID} / \mathrm{NCr}$ & \\
\hline & SR & Large Cell, Immunoblastic & $\mathrm{SCID} / \mathrm{NCr}$ & \\
\hline Liver & $\mathrm{HuH}-7$ & Differentiated Hepatocellular Carcinoma & $\mathrm{nu} / \mathrm{nu} \mathrm{NCr}$ & 2 samples P0 \\
\hline \multirow[t]{9}{*}{ Lung } & A549 & Adenocarcinoma & $\mathrm{nu} / \mathrm{nu} \mathrm{NCr}$ & \\
\hline & A549/Asc-1 & Adenocarcinoma & $\mathrm{nu} / \mathrm{nu} \mathrm{NCr}$ & 3 samples $P 4,2$ samples $P 0$ \\
\hline & EKVX & Adenocarcinoma & $\mathrm{SCID} / \mathrm{NCr}$ & 2 samples P0 \\
\hline & HOP-62 & Adenocarcinoma & $\mathrm{nu} / \mathrm{nu} \mathrm{NCr}$ & 4 samples P1 \\
\hline & HOP-92 & Large Cell, undifferentiated & $\mathrm{nu} / \mathrm{nu} \mathrm{NCr}$ & \\
\hline & $\mathrm{NCl}-\mathrm{H} 226$ & Squamous Carcinoma & $\mathrm{nu} / \mathrm{nu} \mathrm{NCr}$ & 2 samples P1 \\
\hline & $\mathrm{NCl}-\mathrm{H} 23$ & Adenocarcinoma, NSCLC & $\mathrm{nu} / \mathrm{nu} \mathrm{NCr}$ & 2 samples $\mathrm{PO}$ \\
\hline & $\mathrm{NCl}-\mathrm{H} 460$ & Large Cell Carcinoma & $\mathrm{nu} / \mathrm{nu} \mathrm{NCr}$ & \\
\hline & $\mathrm{NCl}-\mathrm{H} 522$ & Adenocarcinoma & $\mathrm{nu} / \mathrm{nu} \mathrm{NCr}$ & 2 samples P0 \\
\hline \multirow[t]{8}{*}{ Melanoma } & A375 & Metastatic Malignant Melanoma & $\mathrm{nu} / \mathrm{nu} \mathrm{NCr}$ & 2 samples $\mathrm{PO}$ \\
\hline & COLO 829 & Malignant Melanoma & $\mathrm{nu} / \mathrm{nu} \mathrm{NCr}$ & 2 samples $\mathrm{PO}$ \\
\hline & LOX IMVI & Malignant Amelanocytic Melanoma & $\mathrm{nu} / \mathrm{nu} \mathrm{NCr}$ & 2 samples P0 \\
\hline & M14 & Adenocarcinoma & $\mathrm{nu} / \mathrm{nu} \mathrm{NCr}$ & 2 samples $\mathrm{PO}$ \\
\hline & MALME-3 M & Malignant Melanoma & $\mathrm{nu} / \mathrm{nu} \mathrm{NCr}$ & 2 samples $\mathrm{PO}, 4$ samples $\mathrm{P} 4$ \\
\hline & MDA-MB-435 & Adenocarcinoma & $\mathrm{nu} / \mathrm{nu} \mathrm{NCr}$ & 2 samples P0, 3 samples P10 \\
\hline & MDA-N ${ }^{d}$ & HER2/ERB2 transfectant of MDA-MB-435 & $\mathrm{nu} / \mathrm{nu} \mathrm{NCr}$ & 2 samples P0 \\
\hline & UACC-62 & Malignant Melanoma & $\mathrm{nu} / \mathrm{nu} \mathrm{NCr}$ & \\
\hline \multirow[t]{3}{*}{ Ovarian } & CP70 & Carcinoma & $\mathrm{nu} / \mathrm{nu} \mathrm{NCr}$ & 2 samples $\mathrm{PO}$ \\
\hline & OVCAR-3 & Adenocarcinoma & $\mathrm{nu} / \mathrm{nu} \mathrm{NCr}$ & 2 samples P0 \\
\hline & OVCAR-5 & Carcinoma & $\mathrm{nu} / \mathrm{nu} \mathrm{NCr}$ & 2 samples $\mathrm{PO}$ \\
\hline Pancreatic & AsPC-1 & Adenocarcinoma & $\mathrm{nu} / \mathrm{nu} \mathrm{NCr}$ & 2 samples $\mathrm{PO}$ \\
\hline \multirow[t]{2}{*}{ Prostate } & $P C-3$ & Adenocarcinoma & Male nu/nu NCr & 2 samples P0 \\
\hline & $\mathrm{PC}-3 / \mathrm{M}^{\mathrm{e}}$ & Metastatic PC-3 subline & Male nu/nu NCr & \\
\hline
\end{tabular}


Table 1 Tumor cell lines, host mice, protocol variances (Continued)

\begin{tabular}{|c|c|c|c|c|}
\hline \multirow[t]{4}{*}{ Renal } & $786-0$ & Adenocarcinoma & $\mathrm{nu} / \mathrm{nu} \mathrm{NCr}$ & \\
\hline & CAKI-1 & Renal Cell Carcinoma & $\mathrm{nu} / \mathrm{nu} \mathrm{NCr}$ & 2 samples P0 \\
\hline & RXF 393 & Poorly Differentiated Hypernephroma & $\mathrm{nu} / \mathrm{nu} \mathrm{NCr}$ & \\
\hline & SN12C & Carcinoma & $\mathrm{nu} / \mathrm{nu} \mathrm{NCr}$ & 2 samples $\mathrm{PO}$ \\
\hline
\end{tabular}

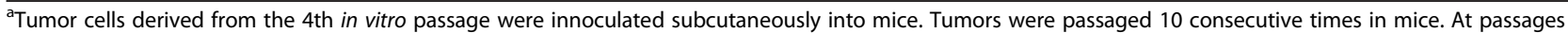
1,4 , and 10 (P1, P4, P10, respectively), 5 tumors were harvested, cut into small pieces and flash frozen in liquid nitrogen. Samples were then processed as described in Methods. For comparative purposes, 3 samples of the in vitro cultivated cells at passage 4 (P0) were also prepared for microarray analysis. ${ }^{\mathrm{b}} 3 \mathrm{mg} / \mathrm{kg}$ Q7D SC Estradiol.

'Matrigel $18.1 \mathrm{mg} / \mathrm{mL}$ P1 only.

${ }^{d}$ HER2/ERBB2 transfectant of MDA-MB-435.

${ }^{\text {PPC3 }}$ subline isolated from liver metastasis in mice.

Genespring GX11 (Agilent, Santa Clara, CA). Results demonstrated one replicate from the PC-3 P10 had control probe errors and it was excluded (Figure 1A). The hybridization was repeated using the original PC-3 P10 RNA sample on a new chip that yielded satisfactory results and was included in further analyses. Lastly, principal component analysis (PCA) was used to identify outliers. For example, results shown in Figure 1B identify one population of arrays segregated from the primary component. Closer inspection identified these .CEL files as passages 4 and 10 of SF-268 and SF-539. This finding suggested a conserved problem with late passage for these lines. We then investigated whether displacement of tumor cells by an outgrowth of mouse cells was responsible for the observed effects. Results from endpoint PCR (Figure 1C) using mouse and human specific primers directed against PTGER2 [14] showed the first in vivo passage of SF-268 and SF-539 tumors contained both mouse and human genomic DNA as expected, but all tumors harvested from 4th and 10th serial passages were devoid of human genomic DNA. The SF-268 and SF-539 models differed from others in the study in that they utilized Matrigel $^{\circ}$ to initially establish tumor growth in passage 1 and they were implanted into NOD.SCID/NCr mice since growth in athymic nu/nuNCr mice was unsuccessful. It is recognized that NOD.SCID/NCr mice have a propensity for spontaneous tumor formation [15] and also it is reasonable to speculate that Matrigel $^{\circ}$ (a growth-factor rich gel secreted by EHS (Engelbreth-Holm-Swarm) mouse sarcoma cells) may encourage spontaneous host cell outgrowth. This emphasizes the need for routine monitoring of mouse outgrowth especially when Matrigel ${ }^{\circ}$, and possibly

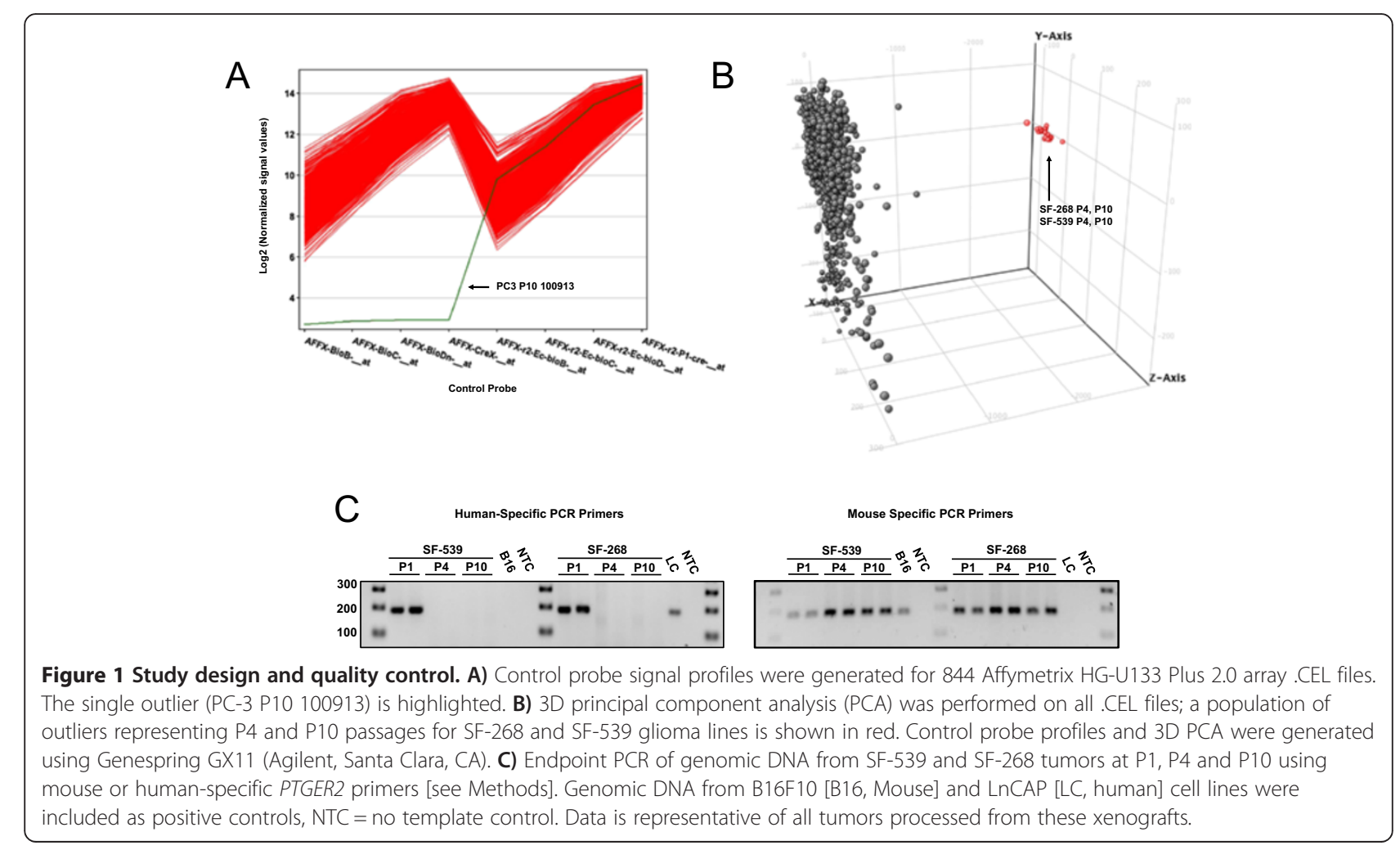


a NOD.SCID background are employed. Although mouse outgrowth was not a problem for the remaining models, this phenomenon should be an important consideration for studies involving serial passage of tumor fragments over extended periods of time. In light of these results, $\mathrm{P} 4$ and P10 samples for SF-268 and SF-539 were not included in this data release.

\section{Hierarchical clustering QC}

All experiments were subjected to hierarchical clustering to confirm similarity in microarray signatures for cell lines and subsequent xenograft passages. Fold-change data [100-fold cut-off] for each parameter was used to generate the hierarchical cluster shown in Additional file 1. This analysis confirmed that for the majority of experiments, the originating cell lines and subsequent in vivo passages clustered together. However, P10 data for CAKI-1, SN12C and RXF 393 renal lines were shown to cluster together, suggesting a high degree of similarity between these samples (Additional file 2A). The identity of these tumors was confirmed by repeating the Identifiler ${ }^{\circ}$ STR analyses. Thus, the clustering of these P10 renal tumors of distinct cell line origins had a biological basis and was not the result of technical errors. Other exceptions involved the co-clustering of MDA-MB-435 and MDA-N (Additional file 2B) along with a similar trend for A549 and A549/ Asc-1 (Additional file 2C). These observations were anticipated given that MDA-N is derived from MDA-MB-435 and A549/Asc- 1 is a tumorigenic clone of A549. Additionally, two breast cancer cell lines (MCF7 and MDAMB-231 T) did not cluster together nor did three ovarian lines (OVCAR-3, CP70, and OVCAR-5) (Additional file 2D and E). Closer scrutiny provides a plausible explanation given these lines differ significantly within their categories. Specifically, MCF7 is an estrogen-dependent $(\mathrm{ER}+)$ tumor whereas MDA-MB-231 T is triple negative (negative for estrogen receptor, progesterone receptor, Her2/neu). Similarly, CP70 and OVCAR-5 are ovarian carcinomas whereas OVCAR-3 is an adenocarcinoma. OVCAR-3 is also ER + while OVCAR-5 is ER negative and CP70 is a cisplatin-resistant subline of A2780. Following quality control, the final dataset comprised 47 complete experiments and 2 partial experiments (P0 and P1 for SF-268 and SF-539) for a total of 823 arrays.

\section{Monitoring changes in transcript expression}

The central goal of this study was to ascertain expression levels for any given transcript across all in vivo models and with successive passage. To this end, normalized gene expression data were generated for all 192 conditions [see Additional file 3, txt file should be copied into EXCEL or other spreadsheet application to view]. Throughout the study, when multiple probe sets were present for the same transcript, the Jetset methodology [16] was used to select the most robust candidate. Data for four example probe sets; 205225_at (ESR1, estrogen receptor alpha), 206426_at (MLANA, melan-A), 201839_s_at (EPCAM, epithelial cell adhesion molecule), and 201746_at (TP53, p53) at P1, P4 and P10 are plotted in Figure 2. Results showed that MCF7 cells expressed the highest level of ESR1 across the panel, consistent with their known estrogen receptor positive status and their absolute dependence on exogenous estradiol for growth in mice. Furthermore, ESR1 expression was shown to increase modestly with passage, suggesting serially passaged tumors remain a valid target for estrogen receptor antagonists. MLANA (Melan-A) is a melanoma-restricted antigen and results show expression to be limited primarily to the melanoma cell lines. MLANA expression was relatively consistent with passage, apart from UACC-62 where levels modestly increase at P10. Similarly, EPCAM is highly expressed on many epithelial cells and results show considerable variation in mRNA expression levels even between epithelial lines. While most tumors had stable expression of EPCAM from P1 to P10, there were a few models with notable changes including A549, CaKi-1 and NCI-H460. The final example, TP53/p53 serves to show the value of integrating relative expression data with pre-existing genetic information. This tumor suppressor and master regulator of the cell cycle is frequently mutated or deleted in tumors $[17,18]$. This analysis confirmed the relative lack of p53 expression in p53-null HL60 cells. However, there was considerable variability in levels of expression for models with mutant $\mathrm{p} 53$. This information could be useful for studies of agents targeting cells with mutant/deleted p53 e.g., the Wee1 inhibitor MK-1775 or mutant p53 oncolytic adenovirus $[19,20]$. Overall, this analysis serves to illustrate the potential of these data within therapeutic studies and provide evidence that mRNA expression can change markedly with in vivo passage.

Another approach to data mining involves plotting the extent of change in expression with passage. To exemplify, analyses were performed on two groups of therapeutically relevant transcripts, those involved in drug resistance and those coding for select receptor tyrosine kinases (RTKs). For resistance genes, expression relative to other models at P1 was plotted (Figure 3A) along with the change in expression from P1 to P10 (Figure 3B). Several noteworthy trends were evident. For HCT-15, a highly MDR drugresistant cell line in culture, expression of the multidrug transporter ABCB1 [MDR1] was the highest relative to other lines at P1. However by P10, the expression had declined to that comparable to other tumors. This suggests HCT-15 tumors may acquire sensitivity to agents such as doxorubicin, paclitaxel and other MDR sensitive agents with serial in vivo passage [21]. This finding is confirmed by in vivo efficacy data for paclitaxel against subcutaneously implanted HCT-15 xenografts (Additional file 4). As 


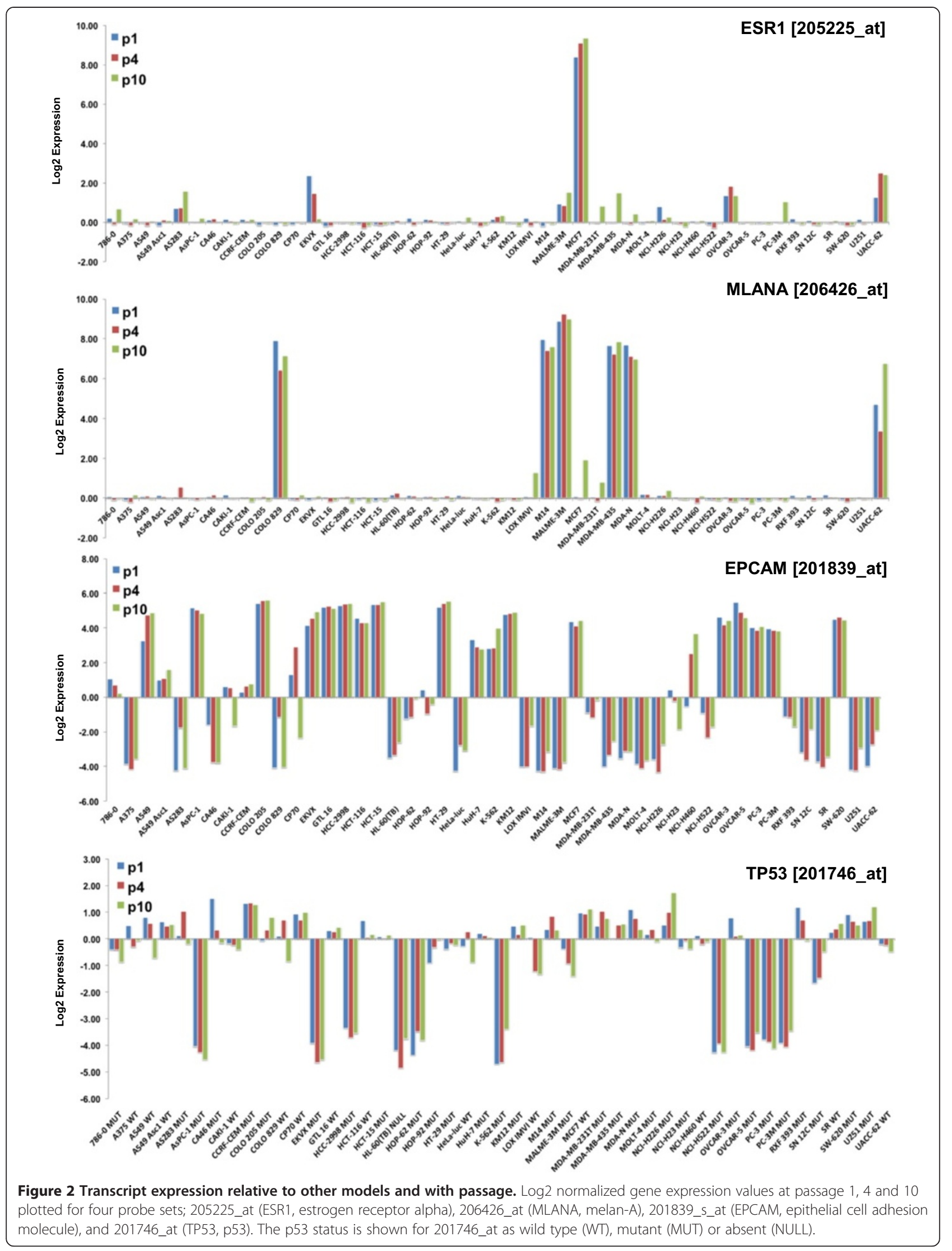




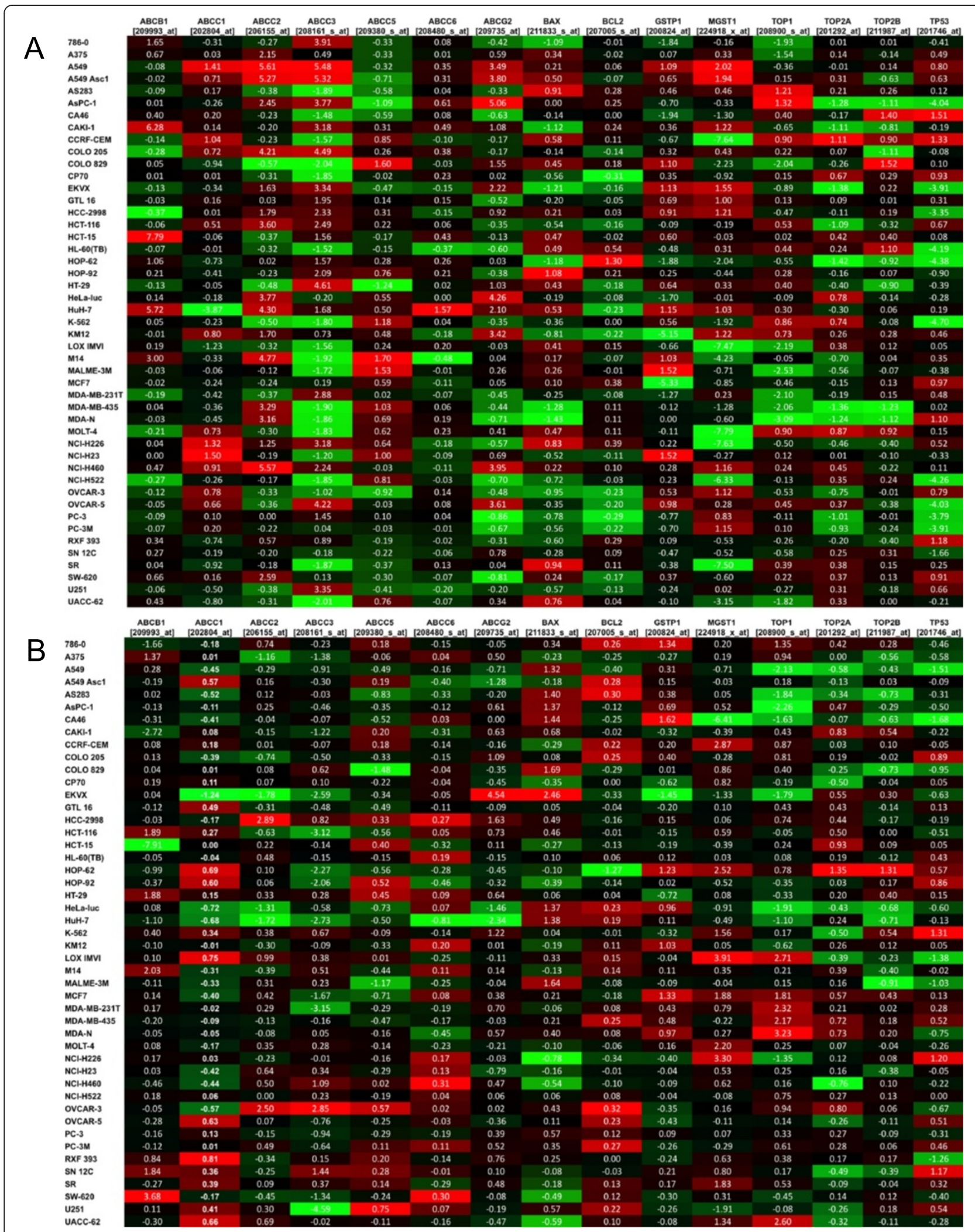

Figure 3 Change in expression from P1 to P10 for a subset of transcripts involved in drug resistance. A) Log2 normalized expression values for each transcript in all models at P1. B) Change in log2 normalized expression for each transcript in all models from P1 to P10. For each probe set, entries are formatted where red is the highest value, green is the lowest and the median is black. 
suggested by the array data, differences in the response of P1 and P8 tumors to paclitaxel treatment were observed. The P1 tumors showed progressive growth in spite of paclitaxel therapy (Additional file 4A). In contrast, the P8 tumors responded to treatment with total growth inhibition (Additional file 4B). Comparison of tumor weights between the P8 vehicle and P8 paclitaxel-treated mice showed statistically significant differences at days 22,26 and 29 with $\mathrm{p}$ values of $0.0004,0.001$, and 0.0001 , respectively. In contrast, there was no difference between the P1 vehicle-treated and paclitaxel-treated groups at any time point. These data support the conclusion that HCT-15 human colon tumor xenografts acquire paclitaxel sensitivity during serial in vivo passage.

Expression of microsomal glutathione S-transferase (MGST) has been shown to confer resistance to cisplatin [22]. In this analysis, expression of MGST1 [224918_x_at] increased with passage in several cell lines such as LOX IMVI and NCI-H226. Given the general trend toward increased expression from P1 to P10, it could be surmised that increased resistance would be observed in serially passaged tumors. This observation is consistent with our data, where evaluation of cisplatin in subcutaneous LOX IMVI xenografts showed sensitivity to cisplatin declines with serial in vivo passage. When cisplatin was administered at the maximum tolerated dose to LOX-IMV1 tumor-bearing mice at $\mathrm{P} 1, \mathrm{P} 4$ and $\mathrm{P} 10$, the optimal percent test/control values were $19 \%, 41 \%$, and $64 \%$, respectively. The $\% \mathrm{~T} / \mathrm{C}$ is inversely related to the tumor sensitivity so the greater the tumor response the lower the $\% \mathrm{~T} / \mathrm{C}$. A $\% \mathrm{~T} / \mathrm{C}$ of $40 \%$ or lower is indicative of antitumor activity [23]. Thus, as predicted by the changes in MGST1 relative expression in LOX IMV1 tumors with serial in vivo passage, P1 tumors were highly sensitive while the P10 tumors were not. The ranking of relative MGST1 expression levels at P1 shows A549/Asc-1 and A549 have the greatest and MOLT-4 the lowest MGST1 expression. This suggests cisplatin would be inactive against A549 tumors and active against MOLT- 4 tumors. This is borne out by in vivo sensitivity testing where MOLT-4 has a statistically significant reduction in tumor growth in mice receiving $3.24 \mathrm{mg}$ cisplatin $/ \mathrm{kg}$ compared to vehicle controls (Additional file 5A) while A549 tumors do not respond even with an increased cisplatin dose $(6.7 \mathrm{mg} / \mathrm{kg})$ and a smaller initial starting tumor size (Additional file 5B).

Interestingly, the reverse trend in mRNA expression was observed in CA46 cells, where MGST1 was downregulated at P10. Here, although no xenograft data exists to confirm this, sensitivity to cisplatin could be predicted to increase with in vivo passage. Lastly increased expression of ABCG2, a transporter that enhances resistance to mitoxantrone, daunorubicin and doxorubicin [24] was noted in EKVX cells from P1 to P10.
Results in Figure 4 show a similar analysis focused on a subset of cancer-related receptor tyrosine kinases. Again, several trends were evident. For example, PC-3 M cells expressed the highest relative levels of KDR (VEGFR2; 203934_at) at P1. However, levels declined by P10, an observation that could have consequences for evaluation of therapeutics targeting this pathway (e.g., sorafenib). The melanoma cell lines M14 and MALME-3 M expressed significant levels of KIT (stem cell factor receptor) [205051_s_at] relative to other models at P1. With serial passage, expression of KIT declined slightly in MALME$3 \mathrm{M}$ by P10 whereas the levels were increased in M14 at P10. Conversely, A549 cells expressed low levels of KIT at P1, but expression increased markedly at P10. These observations may have consequences for experiments where a c-Kit inhibitor (e.g., imatinib) is being evaluated.

\section{A general metric of model stability}

The prior analysis suggested that significant changes in transcript expression occurred in several models from P1 to P10. Therefore, we sought a general metric of stability for each xenograft model. To achieve this, the number of transcripts showing $>3$-fold increase or $>3$-fold decrease $(\mathrm{p}<0.05)$ from P1 to P4 and P1 to P10 was determined for each of 47 models. We reasoned the higher the stability of the model, the smaller the number of transcripts with changes in expression that would be observed between passages. Figure 5 illustrates the results of this analysis, where models such as HL-60 (TB) and MOLT-4 (32 and 66 differentially-expressed transcripts between P1 and P10, respectively) may be defined as highly stable, whereas NCI-H460 and EKVX tumors are markedly altered at P10 (1401 and 1696 differentially expressed transcripts between P1 and P10, respectively) with approximately 50\% of these changes occurring between P1 and P4. From this analysis it is evident that protracted in vivo growth profoundly alters the transcriptome for most models. Generation of a simple metric of stability allows models to be ranked according to the degree of change. Whether these changes represent gradual adaptations to growth in a mouse microenvironment or selection-pressure promoting outgrowth of sub-clones remains to be determined. However, it is interesting to note that a survey of genes (CDH1, FN1, KRT19) related to the epithelialmesenchymal transition (EMT) identified widespread changes in several models with passage (results not shown). Given the recognized effects of EMT on drug sensitivity, this phenomenon may be worthy of further scrutiny [25].

\section{The cell line to xenograft transition}

This dataset can be interrogated to monitor gene expression changes occurring during the immediate transition from in vitro to in vivo growth. However, this analysis is complicated by potential interference from 


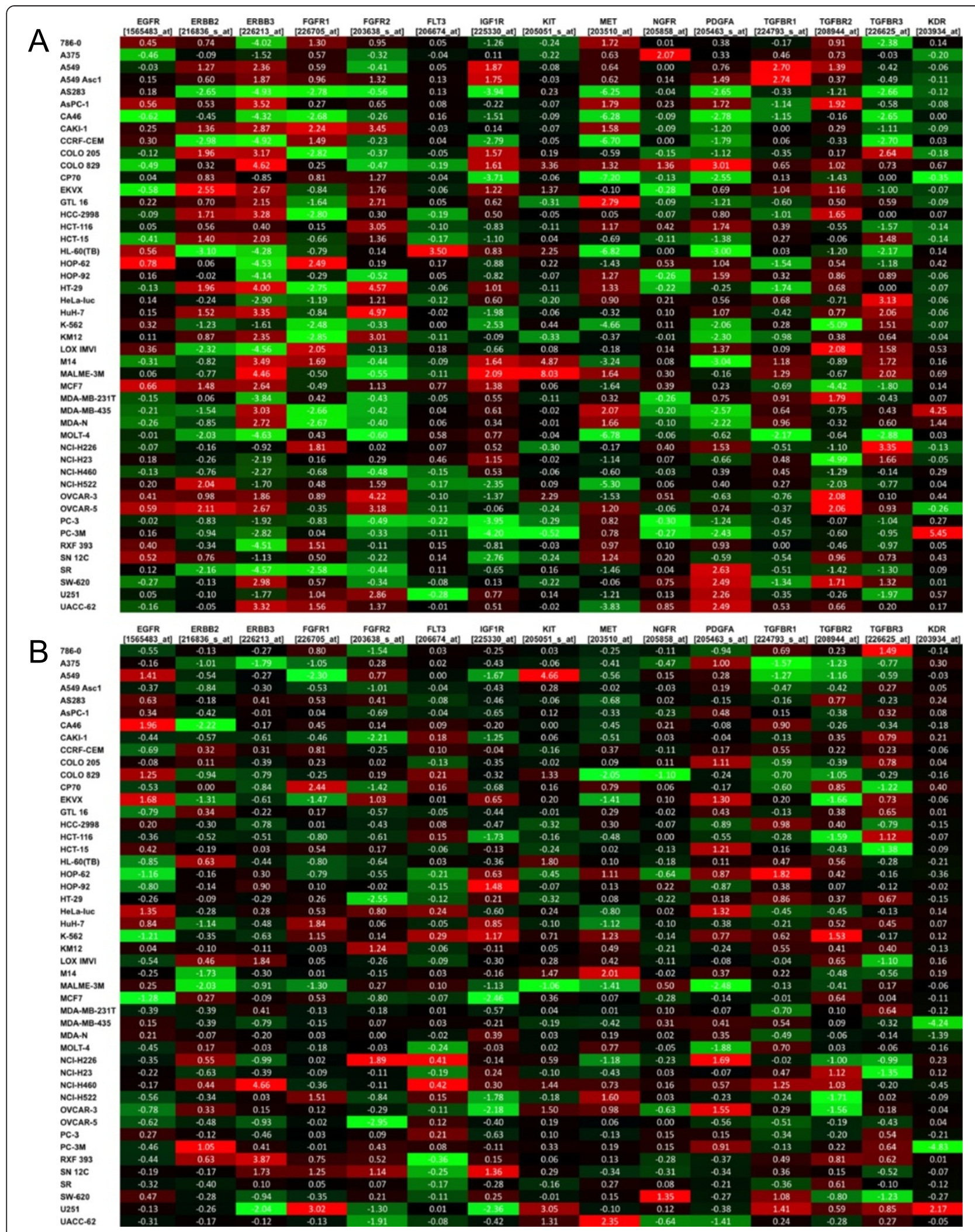

Figure 4 Change in expression from P1 to P10 for a subset of transcripts coding for receptor tyrosine kinases (RTKs). A) Log2

normalized expression values for each transcript in all models at P1. B) Change in log2 normalized expression for each transcript in all models from P1 to P10. For each probe set, entries are formatted where red is the highest value, green is the lowest and the median is black. 


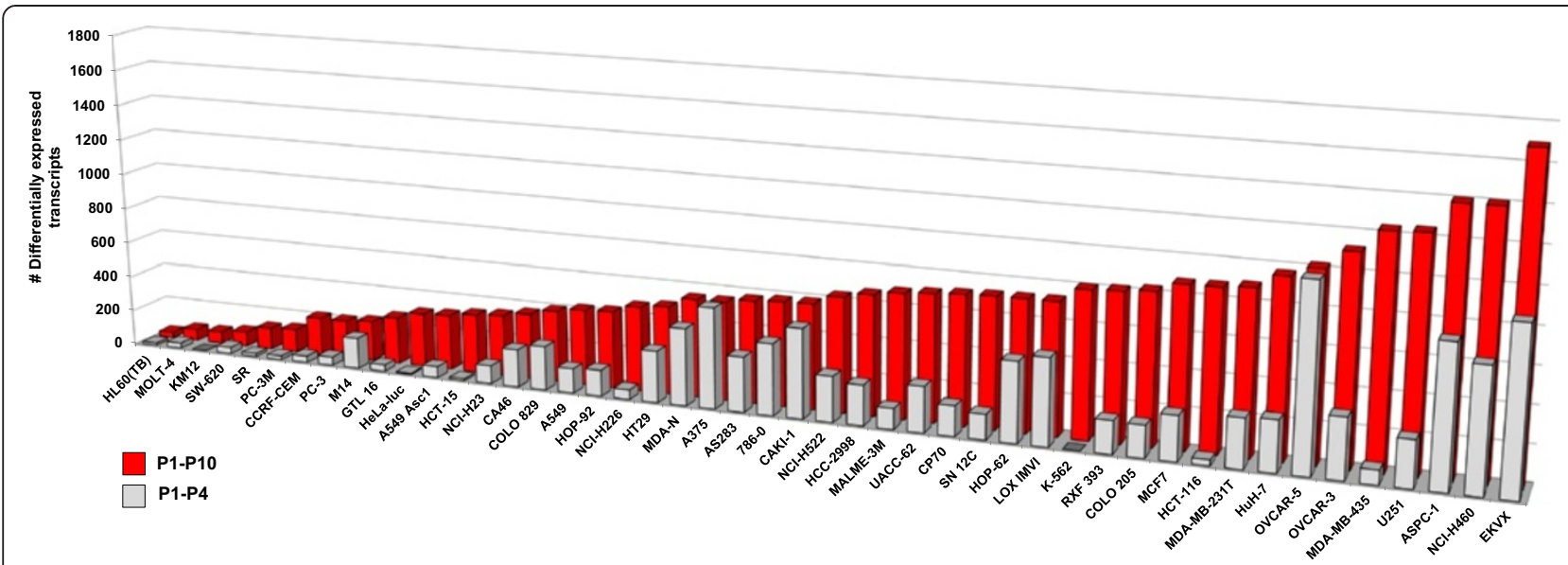

Figure 5 Ranking model stability. For each model, Genespring GX11 was used to generate a list of differentially expressed transcripts for P1 to P4 and P1 to P10 [3-fold cut-off, p<0.05]. The number of differentially regulated transcripts at P1 to P4 and P1 to P10 was then plotted for each model and results sorted in terms of P1 to P10 [lowest to highest] to generate a measure of model stability.

cross-hybridizing mouse mRNA from the xenograft samples. Although cell sorting can remove mouse cell contamination [26], an alternative strategy involves identifying probe sets on the Affymetrix HG-U133 Plus 2.0 array with the potential to cross-hybridize with mouse mRNA and excluding these from analysis or flagging them for additional evaluation. To this end, 5 murine mRNA samples (mouse universal RNA, B16F10 murine melanomas and skin from the C57BL/6 mice bearing the tumor, colon 26 murine tumors and skin from the Balb/c mice bearing the tumor), all performed in triplicate, were applied to the human Affymetrix HG-U133 Plus 2.0 arrays to generate a list of cross-hybridizing probe sets [see Methods]. Mouse RNAs of varied origin were used to provide diversity in the detection of cross-hybridizing events. Results demonstrated a total of 7963 probe sets have the potential to bind mouse mRNA. This includes all possible binding events ranging from just one of the mouse samples cross hybridizing to a probe set to the cross hybridization of all five of the different murine samples. Although relatively large, this list likely includes probe sets that bind nonspecifically to any cDNA population along with those mRNAs showing high homology between mouse and human. Increasing the stringency to 4 and 5 out of 5 murine samples that must bind to a particular probe set before that probe is excluded from the analysis reduces the number of probe sets with the potential to crosshybridize to murine RNA by 3 -fold (to 2614). To provide flexibility to the investigator the list of transcripts with the total number of mouse RNA samples found to crosshybridize to each probe set is shown in Additional file 6.

As an example of the in vitro to in vivo transition, Table 2 shows the results from pairwise analysis of prostate lines (PC-3 and $\mathrm{PC}-3 / \mathrm{M}$ at $\mathrm{P} 0$ ) with their respective $\mathrm{P} 1$ xenografts. The 50 highest up-regulated transcripts before removal of the 14 cross hybridizing probe sets are shown in Table 2, with transcripts showing potential mouse artifacts identified. Hemoglobin epsilon 1 (HBE1) [217683_at] is a probable cross-hybridization event that is important because PC-3 cells are not expected to express this mRNA. Other genes of note that were removed as a result of mouse cross-hybridization include SERPINB6, CXCL1, COL3A1 and ADM. All with the exception of SERPINB6 are genes of the stromal compartment [27-29]. Removal of the mouse cross-hybridizing probes provides greater confidence that observations such as increased expression of IL-8 (202859_x_at), CXCL6 (206336_at), and ANGPTL4 (223333_s_at) represent genuine adaptations of PC-3/PC3-M cells to in vivo growth. These upregulated genes point toward activation of pathways involved in invasion and metastasis [30-32]. Table 3 shows DAVID gene ontology $(\mathrm{GO})$ analysis for the top 50 up-regulated genes following removal of the mouse cross-hybridizing probes. Consistent with the literature [33-37] genes involved in the extracellular matrix (ECM), cell adhesion, chemotaxis, cytokine, immune response, tumor-host interaction and growth factor induced signal transduction were up-regulated in xenograft tumors relative to those cells grown in vitro. A spreadsheet of fold-change data for the P0 to P1 transition (with cross-hybridizing transcripts noted) is shown in Additional file 7. Similar analyses for the P0 to P1 transition for the top 50 up-regulated genes and respective DAVID GO analysis for 9 of the 13 model classes (see Table 1) can be found in Additional file 8.

\section{Conclusions}

The evaluation of cancer therapeutics using xenograft models is a resource-intensive and time-consuming endeavor. Currently, molecular profiling with large-scale genetic, proteomic and metabolic screening technologies 
Table $\mathbf{2}$ Top $\mathbf{5 0}$ up-regulated probe sets in the prostate tumor type

\begin{tabular}{|c|c|c|c|c|c|c|}
\hline $\begin{array}{l}\text { Prostate mouse } \& \\
\text { human probe set ID }\end{array}$ & $\begin{array}{c}\text { Prostate } \\
\text { gene symbol }\end{array}$ & $\begin{array}{l}\text { Prostate } \mathrm{P0}->\mathrm{P} 1 \\
\text { average fold change }\end{array}$ & $\begin{array}{c}\text { \# Mouse } \\
\text { cross-Hyb tissues }\end{array}$ & $\begin{array}{c}\text { Prostate human } \\
\text { probe set ID }\end{array}$ & $\begin{array}{c}\text { Prostate } \\
\text { gene symbol }\end{array}$ & $\begin{array}{c}\text { Prostate } \mathrm{P0}->\mathrm{P} 1 \\
\text { average fold change }\end{array}$ \\
\hline 231628_s_at & SERPINB6 & 8.169 & 5 & 202859_x_at & IL8 & 5.290 \\
\hline 216405_at & & 6.239 & 5 & 206336_at & CXCL6 & 5.190 \\
\hline 217683_at & HBE1 & 6.171 & 5 & 209183_s_at & C10orf10 & 4.672 \\
\hline 202859_x_at & IL8 & 5.290 & & 223333_s_at & ANGPTL4 & 4.479 \\
\hline 206336_at & CXCL6 & 5.190 & & 211506_s_at & IL8 & 4.451 \\
\hline 209183_s_at & C10orf10 & 4.672 & & 201438_at & COL6A3 & 4.328 \\
\hline 204470_at & CXCL1 & 4.551 & 1 & 212977_at & CXCR7 & 4.231 \\
\hline 223333_s_at & ANGPTL4 & 4.479 & & 1570537_a_at & & 4.170 \\
\hline 211506_s_at & IL8 & 4.451 & & 211756_at & PTHLH & 4.153 \\
\hline 201438_at & COL6A3 & 4.328 & & 203828_s_at & IL32 & 3.987 \\
\hline 217572_at & & 4.301 & 5 & 241436_at & SCNN1G & 3.967 \\
\hline 212977_at & CXCR7 & 4.231 & & 214157_at & GNAS & 3.756 \\
\hline 1570537_a_at & & 4.170 & & 221009_s_at & ANGPTL4 & 3.744 \\
\hline 211756_at & PTHLH & 4.153 & & 213711_at & KRT81 & 3.485 \\
\hline 203828_s_at & IL32 & 3.987 & & 206300_s_at & PTHLH & 3.460 \\
\hline 241436_at & SCNN1G & 3.967 & & 1569978_x_at & & 3.456 \\
\hline 215076_s_at & COL3A1 & 3.775 & 5 & 211071_s_at & MLLT11 & 3.355 \\
\hline 202912_at & ADM & 3.763 & 1 & 201578_at & PODXL & 3.249 \\
\hline 214157_at & GNAS & 3.756 & & 222449_at & PMEPA1 & 3.230 \\
\hline 221009_s_at & ANGPTL4 & 3.744 & & 205199_at & CA9 & 3.189 \\
\hline 224344_at & COX6A1 & 3.700 & 5 & 201890_at & RRM2 & 3.106 \\
\hline 213711_at & KRT81 & 3.485 & & 211030_s_at & SLC6A6 & 3.100 \\
\hline 201852_x_at & COL3A1 & 3.483 & 5 & 222608_s_at & ANLN & 3.062 \\
\hline 206300_s_at & PTHLH & 3.460 & & 210095_s_at & IGFBP3 & 3.028 \\
\hline 1569978_x_at & & 3.456 & & 207291_at & PRRG4 & 3.006 \\
\hline 211071_s_at & MLLT11 & 3.355 & & 209774_x_at & $\mathrm{CXCL2}$ & 2.979 \\
\hline 201578_at & PODXL & 3.249 & & 211161_s_at & COL3A1 & 2.974 \\
\hline 222449_at & PMEPA1 & 3.230 & & 206157_at & PTX3 & 2.970 \\
\hline 205199_at & CA9 & 3.189 & & 203373_at & SOCS2 & 2.969 \\
\hline 201890_at & RRM2 & 3.106 & & 232381_s_at & DNAH5 & 2.929 \\
\hline 211030_s_at & SLC6A6 & 3.100 & & 212143_s_at & IGFBP3 & 2.928 \\
\hline 1570107_at & & 3.091 & 5 & 238513_at & PRRG4 & 2.922 \\
\hline 222608_s_at & ANLN & 3.062 & & 201291_s_at & TOP2A & 2.911 \\
\hline 210095_s_at & IGFBP3 & 3.028 & & 202404_s_at & COL1A2 & 2.908 \\
\hline 207291_at & PRRG4 & 3.006 & & 205479_s_at & PLAU & 2.892 \\
\hline 209270_at & LAMB3 & 3.002 & 2 & 205680_at & MMP10 & 2.803 \\
\hline 209774_x_at & CXCL2 & 2.979 & & 217875_s_at & PMEPA1 & 2.797 \\
\hline 211161_s_at & COL3A1 & 2.974 & & 230280_at & TRIM9 & 2.763 \\
\hline 206157_at & PTX3 & 2.970 & & 227556_at & NME7 & 2.723 \\
\hline 203373_at & SOCS2 & 2.969 & & 242517_at & KISS1R & 2.699 \\
\hline 232381_s_at & DNAH5 & 2.929 & & 218691_s_at & PDLIM4 & 2.688 \\
\hline 212143_s_at & IGFBP3 & 2.928 & & 219148_at & PBK & 2.684 \\
\hline 238513_at & PRRG4 & 2.922 & & 203691_at & $\mathrm{PI3}$ & 2.684 \\
\hline
\end{tabular}


Table 2 Top 50 up-regulated probe sets in the prostate tumor type (Continued)

\begin{tabular}{|c|c|c|c|c|c|c|}
\hline 201291_s_at & TOP2A & 2.911 & & 202998_s_at & LOXL2 & 2.681 \\
\hline 202404_s_at & COL1A2 & 2.908 & & 210538_s_at & BIRC3 & 2.669 \\
\hline 223484_at & C15orf48 & 2.896 & 1 & 229435_at & GLIS3 & 2.667 \\
\hline 205479_s_at & PLAU & 2.892 & & 41469_at & $\mathrm{Pl} 3$ & 2.649 \\
\hline 227140_at & INHBA & 2.830 & 1 & 218355_at & KIF4A & 2.624 \\
\hline 211668_s_at & PLAU & 2.829 & 1 & 214438_at & HLX & 2.623 \\
\hline 205680_at & MMP10 & 2.803 & & 209156_s_at & COL6A2 & 2.597 \\
\hline
\end{tabular}

Left table includes all probe sets, the mouse RNA binding probe sets are identified by the number of cross hybridizing mouse tissue probes that occurred (1-5 see column 4). Right side of table shows the top 50 human up-regulated probe sets following removal of the mouse component.

is emerging as a powerful tool to improve and guide model selection. In this study, cDNA microarray data was generated for 49 xenograft models routinely used within the Developmental Therapeutics Program at the NCI. The majority of these tumor cell lines are available to the research community through the DCTD Tumor Repository (NCI at Frederick) thus allowing this data to provide guidance for other research studies. Aside from the obvious utility of ranking models in terms of transcript expression for specific genes of interest, analysis demonstrated that prolonged in vivo passage markedly alters the transcriptome of many models. This observation emphasizes the importance of maintaining passage consistency to minimize experimental artifacts. Similarly, these findings provide one explanation for the difficulties reported in reproducing experimental data since the methods for generating test tumors can impact the study profoundly [38]. These data are deposited at http://dtp.nci.nih.gov/microxeno/download.html and in the Gene Expression Omnibus (http:// www.ncbi.nlm.nih.gov/geo/) under accessions GSE48433 and GSE49353. All subsequent data releases will be deposited in the same locations.

\section{Methods}

\section{Cell lines and mice}

All cell lines were obtained from the Division of Cancer Treatment and Diagnosis Tumor Repository (DTP, National Cancer Institute at Frederick, Frederick, MD) or American Type Culture Collection (ATCC) (Manassas, $\mathrm{Va}$ ). In addition, the identities of all cell lines used in this

Table 3 DAVID Gene Ontology (GO) functional annotation on the prostate tumor models during their transition from in vitro to in vivo growth

\begin{tabular}{|c|c|c|c|c|c|c|}
\hline Accession & $\begin{array}{l}\text { Gene Ontology Term generated from DAVID } \\
\text { analysis of human-RNA-only-binding probe sets }\end{array}$ & Gene count & PValue & Fold enrichment & Benjamini & $\begin{array}{l}\text { False discovery } \\
\text { rate }(\%)\end{array}$ \\
\hline GO:0044421 & extracellular region part & 14 & $4.68 \mathrm{E}-07$ & 5.33 & $4.12 \mathrm{E}-05$ & $5.07 \mathrm{E}-04$ \\
\hline GO:0005615 & extracellular space & 12 & 8.91E-07 & 6.40 & $3.92 \mathrm{E}-05$ & $9.65 \mathrm{E}-04$ \\
\hline GO:0005576 & extracellular region & 18 & $3.26 \mathrm{E}-06$ & 3.27 & $9.55 \mathrm{E}-05$ & $3.53 \mathrm{E}-03$ \\
\hline GO:0005578 & proteinaceous extracellular matrix & 7 & $1.75 E-04$ & 7.99 & $3.84 \mathrm{E}-03$ & 0.19 \\
\hline GO:0031012 & extracellular matrix & 7 & 2.63E-04 & 7.41 & 4.61E-03 & 0.28 \\
\hline GO:0009611 & response to wounding & 7 & 0.0019 & 5.10 & 0.6674 & 2.70 \\
\hline GO:0019932 & second-messenger-mediated signaling & 5 & 0.0027 & 8.22 & 0.5559 & 3.96 \\
\hline GO:0001568 & blood vessel development & 5 & 0.0032 & 7.89 & 0.4668 & 4.58 \\
\hline GO:0001944 & vasculature development & 5 & 0.0035 & 7.70 & 0.4022 & 4.99 \\
\hline GO:0005581 & collagen & 3 & 0.0039 & 31.30 & 0.0553 & 4.11 \\
\hline GO:0048870 & cell motility & 5 & 0.0071 & 6.30 & 0.4510 & 9.91 \\
\hline GO:0051674 & localization of cell & 5 & 0.0071 & 6.30 & 0.4510 & 9.91 \\
\hline GO:0008009 & chemokine activity & 3 & 0.0072 & 22.88 & 0.6673 & 8.26 \\
\hline GO:0006935 & chemotaxis & 4 & 0.0074 & 9.66 & 0.4245 & 10.41 \\
\hline GO:0042330 & taxis & 4 & 0.0074 & 9.66 & 0.4245 & 10.41 \\
\hline GO:0001501 & skeletal system development & 5 & 0.0081 & 6.06 & 0.4132 & 11.24 \\
\hline GO:0042379 & chemokine receptor binding & 3 & 0.0081 & 21.48 & 0.4633 & 9.29 \\
\hline GO:0005125 & cytokine activity & 4 & 0.0166 & 7.20 & 0.5732 & 18.13 \\
\hline GO:0005201 & extracellular matrix structural constituent & 3 & 0.0236 & 12.24 & 0.5992 & 24.90 \\
\hline
\end{tabular}


study were confirmed using Identifiler ${ }^{\circledR}$ STR genotyping (Applied Biosystems). All mice used in the study were obtained from the Animal Production Program (National Cancer Institute at Frederick, Frederick, MD). All studies were conducted in an Association for Assessment and Accreditation of Laboratory Animal Care International (AAALACi) accredited facility under a protocol approved by the NCI at Frederick Animal Care and Use Committee. This facility operates under an Office of Laboratory Animal Welfare (OLAW) assurance in compliance with the U.S. Public Health Service Policy on Humane Care and Use of Animals (1996) and the Guide for the Care and Use of Laboratory Animals Eighth Edition. PCR primers were purchased from ABI (Applied Biosystems). Karyotype analysis and STR genotyping results for most seed lines are available at http://dtp.cancer.gov/branches/btb/characterizationNCI60.html.

\section{Tumor growth, propagation and sampling}

Tumor cells for inoculation were derived from the 4th in vitro passage from cryopreserved cell stocks. Cells $(1 \times$ $10^{7}$ cells $/ 0.1 \mathrm{ml} /$ inoculation) were inoculated subcutaneously into mice ( $\mathrm{n}=10$ or more mice depending on the tumor cell line). For comparative purposes, 2-3 samples of in vitro cultivated cells at passage 4 (same as used for in vivo implantation) were also prepared for microarray analysis (P0). When tumors at passage 1 (P1), passage 4 (P4) and passage 10 (P10) reached approximately $500 \mathrm{mg}$ $(10 \times 10 \mathrm{~mm}), 5$ tumors were harvested, cut into small pieces and flash frozen in liquid nitrogen using pre-chilled cryovials. Samples were transferred to a $-70^{\circ} \mathrm{C}$ freezer for holding prior to processing. Serial tumor passage was achieved by harvesting donor tumor material ( $\mathrm{n}=2$ to 5 donors) at each passage, mincing the tumors $(2 \times 2 \mathrm{~mm}$ fragments), pooling the samples and inoculating the recipients subcutaneously using tumor implant trocars. Athymic nude mice (athymic $\mathrm{NCr}-\mathrm{nu} / \mathrm{nu}$ ) served as the primary host for most xenograft studies. In several instances [particularly with human leukemias and lymphomas] it was difficult to establish and passage tumors in athymic nude mice. In these instances, SCID/NCr or NOD.SCID/NCr mice were assessed for suitability. In general, female mice were used as they are less aggressive, easily group-housed and are routinely used in xenograft experiments. Male mice were used for prostate tumors (PC-3, PC-3/M). Two tumors (SF-268 and SF-539) required the use of Matrigel ${ }^{\mathrm{mm}}$ (Collaborative Research, Bectin Dickinson, Bedford, Ma) during the initial tumor cell inoculation to achieve progressive tumor growth. Finally, in those instances where hormone effects on tumor growth are important (e.g., estradiol-dependent breast cancers) mice were supplemented with estradiol (up to $3 \mathrm{mg} / \mathrm{kg}$ ) administered subcutaneously once weekly to maintain progressive tumor growth. Exceptions to the standard protocol are noted in Table 1.

\section{Comparison of HCT-15 sensitivity to paclitaxel at early and late in vivo passage}

In vivo antitumor activity assays were performed with six-week-old female athymic nude mice (Animal Production Program, Frederick, MD). Forty mice were each implanted subcutaneously with $1 \times 10^{7}$ HCT-15 human colon cancer cells (DCTD Repository, Frederick, MD). Thirty of these passage 1 (P1) tumor-bearing mice were randomized into 2 groups $(n=20$ /vehicle control group and 10/treated group) and the remaining tumors were used to serially passage the tumors. For this, tumors were harvested from donor mice, cut into fragments of $2-3 \mathrm{~mm}$ and the resulting fragments were implanted subcutaneously into recipient mice using a tumor implant trocar. This process was repeated when the tumors reached 500-750 mg until the tumors reached their eighth in vivo passage (P8). At $\mathrm{P} 8$, tumor-bearing animals were randomized into 2 groups $(n=18 /$ vehicle control group and 9/treated group). At P1 and P8 the vehicle control groups received $12.5 \%$ cremaphor $/ 12.5 \%$ ethanol $/ 75 \%$ saline while the treated group received $10 \mathrm{mg}$ paclitaxel $/ \mathrm{kg}$. Both treatments were administered intravenously (IV) once daily for 5 days (QDx5) using a standard dosing volume of $10 \mathrm{ml} / \mathrm{kg}$ body weight. Tumor growth was monitored by caliper measurements, and tumor weights were calculated as: [tumor length in $\mathrm{mm} \times{\text { (tumor } \text { width }^{2}}^{2}$ in $\mathrm{mm}$ )] $/ 2$ = weight in $\mathrm{mg}$ (1). Tumor measurements were collected every 3 to 4 days throughout the course of the study. Student's t-test was used to assess the significance in response of the paclitaxel treated animals to the corresponding controls with significance set at a $p$ value of 0.05 or less. The studies were terminated $12-15$ days after the last drug dose.

\section{In vivo sensitivity testing of MOLT-4 and A549 xenografts to cisplatin treatment}

In vivo antitumor activity assays were performed with six-week-old female athymic nude mice (Animal Production Program, Frederick, MD). MOLT-4 and A549 tumors were established in cohorts of mice for evaluation of cisplatin sensitivity. When MOLT-4 tumors reached a median of $150 \mathrm{mg}$ the mice were randomized into vehicle control $(n=20)$ and cisplatin treated groups $(n=10)$. The vehicle control group received $0.9 \%$ saline while the cisplatin was administered at $3.24 \mathrm{mg} / \mathrm{kg}$. When A549 tumors reached a median of $110 \mathrm{mg}$ the mice were randomized into vehicle control $(n=15)$ and cisplatin-treated groups $(n=6)$. The vehicle control group received $0.9 \%$ saline while the cisplatin was administered at $6.7 \mathrm{mg} / \mathrm{kg}$. All treatments were administered intraperitoneally (IP) at one dose per day every fourth day for a total of 3 doses (Q4Dx3) using a standard dosing volume of $10 \mathrm{ml} / \mathrm{kg}$ body weight. Tumor growth was monitored as noted above. The studies were terminated when control tumor 
weights exceeded $2500 \mathrm{mg}$ or 3 weeks post-last drug dose, whichever occurred first.

\section{Tumor homogenization and RNA Isolation}

Frozen xenograft tumor specimens were removed from the freezer and kept in liquid nitrogen. Tumors were cut into smaller pieces using a pill cutter pre-chilled by submersion into liquid nitrogen. A tumor fragment was placed into the pill cutter and quickly cut into smaller pieces (approximately 10-25 milligrams each). The tumor samples were homogenized in RLT-ME buffer (Qiagen, Germantown, MD) using a single $5 \mathrm{~mm}$ steel bead per sample in a Tissuelyser (Qiagen, Germantown, MD) for two minutes at $28 \mathrm{~Hz}$. The volume of RLT-ME buffer for each sample was calculated using a standard formula of $20 \mu \mathrm{L}$ RLT-ME per mg of tissue. Samples were incubated at RT for $10 \mathrm{~min}$ after homogenization following which the tumor material was further homogenized using a QiaShredder column. The RNA was extracted using RNeasy ${ }^{\circ}$ Mini Kits (Qiagen, Germantown, MD) following the manufacturer's protocol. The tumor cells $\left(5-7 \times 10^{6}\right)$ were harvested from sub-confluent flasks at passage 4 by scraping. Following centrifugation, the cell pellets were flash-frozen in liquid nitrogen and stored at $-80^{\circ} \mathrm{C}$. RNA from the cell pellets was isolated using the RNeasy ${ }^{\circ}$ Mini Kit following the manufacturer's protocol.

\section{RNA quantitation and quality control}

Following extraction, RNA quantitation was performed using a Nanodrop spectrophotometer (Thermo Scientific, Wilmington, DE). Microelectrophoresis was performed on all samples using an Agilent Bioanalyzer (Santa Clara, CA) to assess sample quality. The Agilent software algorithm evaluates the entire electrophoretic trace to estimate the total RNA integrity in a sample. The algorithm calculates an RNA Integrity Number (RIN), which classifies the quality of the RNA on a numeric system from 1 to 10 , with 1 being the most degraded and 10 being the most intact. The RIN number allows comparison of the quality of the RNA between samples and ensures better reproducibility. In this study, $73 \%$ of RNA samples scored a RIN of $>9$, while $25 \%$ had a RIN of 7-9 and 2\% had a RIN 5.7-7.

\section{Microarray analysis}

The RNA samples were submitted to Expression Analysis, Inc. (Durham, $\mathrm{NC}$ ) for microarray analysis using the HG-U133 Plus 2.0 array (Affymetrix, Santa Clara, CA). Samples were prepared and hybridized according to the "Affymetrix Technical Manual" (www.expressionanalysis. com). Following staining of the microarray, the fluorescent images were detected in a GeneChip Scanner 3000 and expression data were extracted using the GeneChip Command Console Software (AGCC) v 2.0 (Affymetrix). All GeneChips were scaled to a median intensity setting of
500. Raw array (.CEL files) data are available for direct download from the Developmental Therapeutics Program (http://dtp.nci.nih.gov/microxeno/download.html) and from the Gene Expression Omnibus (http://www.ncbi. nlm.nih.gov/geo/), accessions GSE49353 and GSE48433.

Microarray data were analyzed using the default 'guided workflow' option within Genespring 12.6.1 (Agilent, Santa Clara, CA). In brief, raw data (.CEL) files were imported and replicates assigned to relevant conditions (e.g. 786-0 P0). All data files within the experiment were then normalized using RMA [39], to generate a spreadsheet containing $\log 2$ normalized gene expression values. Next, probe sets were filtered with reference to flags [attributes that denote poor quality entities] along with a percentile cut-off (20\%) - which makes the assumption that $20 \%$ of the probe sets on any given genome-wide array have intensity values that represent noise (since they are not expressed). Next, significance was determined by performing one-way ANOVA $\mathrm{p}<0.05$. For the remaining observations a fold change cut-off could then be applied [default $+/-2$ fold].

\section{Mouse/human endpoint PCR}

As described in Alcoser et al. [14] human- or mousespecific forward primers from the prostaglandin E receptor 2 (PTGER2) gene were used to amplify 189 bp fragments, thereby identifying the presence of mouse DNA and/or human DNA in each tissue/cell sample. Human-specific primers: Forward, 5'- gctgcttctcattgtctcgg-3'; Reverse, $5^{\prime}$ - gccaggagaatgaggtggtc- $3^{\prime}$. Mouse-specific primers: Forward, 5' - cctgctgcttatcgtggctg-3'; Reverse, 5' - gccag gagaatgaggtggtc- $3^{\prime}$. PCR was performed using neutralized, unpurified tissue/cell lysate on an ABI-2720 Thermocycler (Applied Biosystems). PCR conditions: $95^{\circ} \mathrm{C}-5 \mathrm{~min}, 30$ cycles of $\left(95^{\circ} \mathrm{C}-45 \mathrm{sec}, 60^{\circ} \mathrm{C}-30 \mathrm{sec}\right.$, $72^{\circ} \mathrm{C}-90 \mathrm{sec}$ ), $72^{\circ} \mathrm{C}-10 \mathrm{~min}$. DNA bands were resolved on a $2 \%$ agarose gel containing ethidium bromide $(0.5 \mathrm{mg} / \mathrm{ml})$.

\section{Identification of probe sets on Affymetrix U133 Plus 2 array with the potential to cross-hybridize with mouse transcripts}

Array data were generated for 5 different mouse RNA populations hybridized to human Affymetrix U133 Plus 2 chips (3 replicates for each biological sample). The samples were A) mouse Universal RNA (Strategene, La Jolla, CA), B) B16F10 murine melanoma tumors, C) skin from C57BL/6 mice bearing B16F10 tumors, D) colon 26 murine tumors, and E) skin from Balb/C mice bearing Colon 26 tumors. Mouse RNAs of varied origin were used to provide a diversity of mouse transcripts for subsequent qualitative detection of array binding. The 15 txt files generated (5 biological samples, 3 replicates each) were interrogated and for each sample type, all probe sets with a PPP, PPM or PPA [ $\mathrm{P}=$ present, $\mathrm{M}=$ marginal, $\mathrm{A}=$ absent] detection call were sorted into a separate 
file (total 5 files). Each letter of the PPP or PPM, or PPA nomenclature represents 1 array from the triplicate samples. The five lists of probes were combined into a single file and the Microsoft Excel utility DigDb [www.Digdb.com] was used to remove redundancy and to determine how many biological samples contained detectable transcript (shown as PPX ID in \# Mouse Tissues out of five). The resultant list of probe sets and number of mouse RNA samples in which they are called present (PPX) can be found in Additional file 7.

\section{Availability of supporting data}

The data sets supporting the results of this article are available for direct download from the Developmental Therapeutics Program (http://dtp.nci.nih.gov/microxeno/ download.html) and from the Gene Expression Omnibus (http://www.ncbi.nlm.nih.gov/geo/), accessions GSE49353 and GSE48433 as well as in the Additional Files.

\section{Additional files}

Additional file 1: Hierarchical clustering of cell line and xenograft samples. 823 arrays [47 complete models] were uploaded into Genespring (Agilent, Santa Clara, CA) using the Affymetrix expression guided workflow and data normalized using RMA. Entities were then assigned and log2 gene expression data generated for those transcripts that met the following criteria: percentile cut-off $=20$, ANOVA $p<0.05$, probe sets must be differentially expressed $+/-100$ fold in 1 group. The probe sets meeting these criteria were then subjected to Hierarchical clustering according to both conditions [cell lines/passages] and entities [probe sets] with a Pearson absolute distance metric and centroid linkage.

Additional file 2: Issues identified during Hierarchical clustering. Additional file 3: RMA normalized log2 gene expression data for all 49 models - unfiltered, includes all probe sets on the U133 Plus 2.0 Array.

Additional file 4: Antitumor efficacy of paclitaxel against HCT-15 xenografts at passages 1 (P1) and 8 (P8). Vehicle treated mice received $12.5 \%$ cremaphor/12.5\% ethanol/75\% saline QDx5 IV while paclitaxel was administered at $10 \mathrm{mg} / \mathrm{kg}$ QDx5 IV. Statistically significant differences between the treated and control mice were determined with Student's t-test, those points with significant paclitaxel responses are designated by showing the $p$ value adjacent to the data point. A) P1 tumors B) P8 tumors.

Additional file 5: Antitumor efficacy of cisplatin against MOLT-4 and $\mathbf{A} 549$ xenografts. Vehicle treated mice received $0.9 \%$ saline once every 4 days for 3 treatments (Q4Dx3) by the intraperitoneal (IP) route. Statistically significant differences between the treated and control mice were determined with Student's t-test, those points with significant cisplatin responses are designated by with the $\mathrm{p}$ value adjacent to the data point A) MOLT-4 xenografts, the cisplatin dose was $3.24 \mathrm{mg} / \mathrm{kg}$. B) A549 xenografts, the cisplatin dose was $6.7 \mathrm{mg} / \mathrm{kg}$.

Additional file 6: List of transcripts identified as cross-hybridizing with mouse CDNA.

Additional file 7: Change in expression $(\log 2)$ across the entire U133 plus 2 array for all models from P0 to P1 with crosshybridizing probe sets shown.

Additional file 8: A) Top 50 up-regulated probe sets in 9 of 13 tumor types. Left table includes all probe sets, where mouse cross-hybridizing probe sets are shaded grey. Right table shows the top 50 up-regulated probe sets following removal of the cross hybridizing component. B) DAVID gene ontology (GO) functional annotation for each tumor model during transition from in vitro to in vivo growth.
Competing interests

The authors declare that they have no competing interests.

\section{Authors' contributions}

MGH had overall responsibility for study design, execution, analysis and manuscript production. LHS and DLN participated in analysis and interpretation of data and manuscript production, SYA participated in analysis and interpretation of data, $\mathrm{BCO}$ in analysis and interpretation of data, $\mathrm{CAB}, \mathrm{SDB}, \mathrm{RD}$, KD, GK, DJK, AM, MEM, SH, EJH participated in data generation, SLH and MK participated in interpretation and analysis of the data, JC participated in study design. All authors read and approved the final manuscript.

\section{Acknowledgements}

This project has been funded in whole or in part with federal funds from the National Cancer Institute, National Institutes of Health, under Contract No. HHSN261200800001E. The content of this publication does not necessarily reflect the views or policies of the Department of Health and Human Services, nor does mention of trade names, commercial products, or organizations imply endorsement by the U.S. Government. This research was supported [in part] by the Developmental Therapeutics Program in the Division of Cancer Treatment and Diagnosis of the National Cancer Institute. NCI-Frederick is accredited by AAALAC International and follows the Public Health Service Policy for the Care and Use of Laboratory Animals. All animals used in this research project were cared for and used humanely according to the following policies: The U.S. Public Health Service Policy on Humane Care and Use of Animals (1996); the Guide for the Care and Use of Laboratory Animals Eighth Edition; and the U.S. Government Principles for Utilization and Care of Vertebrate Animals Used in Testing, Research, and Training (1985). All studies were approved by the $\mathrm{NCl}$ at Frederick Animal Care and Use Committee (ACUC) prior initiation of work. The $\mathrm{NCl}$ at Frederick ACUC operates under an active Office of Laboratory Animal Welfare assurance.

\section{Author details}

'Biological Testing Branch, National Cancer Institute at Frederick, 1050 Boyles Street, Building 1043, Room 11, Frederick, MD 21702, USA. Biological Testing Branch, Developmental Therapeutics Program, Leidos Biomedical Research, Inc., Frederick National Laboratory for Cancer Research, Frederick, MD 21702, USA. ${ }^{3}$ Biological Testing Branch, Developmental Therapeutics Program, National Cancer Institute at Frederick, Frederick, MD 21702, USA. ${ }^{4}$ Thermo Fisher, 134 Yorkshire Boulevard, Indianapolis, IN, USA. Information Technology Branch, Developmental Therapeutics Program, Division of Cancer Treatment and Diagnosis, NCl, Bethesda, MD 20892, USA. ${ }^{6}$ Molecular Pharmacology Branch, Developmental Therapeutics Program, National Cancer Institute at Frederick, Frederick, MD 21702, USA. 7Developmental Therapeutics Program, Division of Cancer Treatment and Diagnosis, NCl, Bethesda, MD 20892, USA.

Received: 18 November 2013 Accepted: 9 May 2014

Published: 22 May 2014

\section{References}

1. Hollingshead MG: Antitumor efficacy testing in rodents. J Nat/ Cancer Inst 2008, 100(21):1500-1510.

2. Whiteford CC, Bilke S, Greer BT, Chen Q, Braunschweig TA, Cenacchi N, Wei JS, Smith MA, Houghton P, Morton C, Reynolds CP, Lock R, Gorlick R, Khanna C, Thiele CJ, Takikita M, Catchpoole D, Hewitt SM, Khan J: Credentialing preclinical pediatric xenograft models using gene expression and tissue microarray analysis. Cancer Res 2007, 67(1):32-40

3. Weinstein JN: Integromic analysis of the $\mathrm{NCl}-60$ cancer cell lines. Breast Dis 2004, 19:11-22

4. Holbeck S, Chang J, Best AM, Bookout AL, Mangelsdorf DJ, Martinez ED: Expression profiling of nuclear receptors in the $\mathrm{NCl} 60$ cancer cell panel reveals receptor-drug and receptor-gene interactions. Mol Endocrinol 2010, 24(6):1287-1296.

5. Scherf U, Ross DT, Waltham M, Smith LH, Lee JK, Tanabe L, Kohn KW, Reinhold WC, Myers TG, Andrews DT, Scudiero DA, Eisen MB, Sausville EA, Pommier Y, Botstein D, Brown PO, Weinstein JN: A gene expression database for the molecular pharmacology of cancer. Nat Genet 2000, 24(3):236-244 
6. Sausville EA, Holbeck SL: Transcription profiling of gene expression in drug discovery and development: the $\mathrm{NCl}$ experience. Eur J Cancer 2004 40(17):2544-2549.

7. Liu H, D'Andrade P, Fulmer-Smentek S, Lorenzi P, Kohn KW, Weinstein JN, Pommier $Y$, Reinhold WC: mRNA and microRNA expression profiles of the $\mathrm{NCl}-60$ integrated with drug activities. Mol Cancer Ther 2010, 9(5):1080-1091.

8. Gmeiner WH, Reinhold WC, Pommier Y: Genome-wide mRNA and microRNA profiling of the $\mathrm{NCl} 60$ cell-line screen and comparison of FdUMP [10] with fluorouracil, floxuridine, and topoisomerase 1 poisons. Mol Cancer Ther 2010, 9(12):3105-3114.

9. Nishizuka S, Charboneau L, Young L, Major S, Reinhold WC, Waltham M, Kouros-Mehr H, Bussey KJ, Lee JK, Espina V, Munson PJ, Petricoin E 3rd, Liotta LA, Weinstein JN: Proteomic profiling of the $\mathrm{NCl}-60$ cancer cell lines using new high-density reverse-phase lysate microarrays. Proc Natl Acad Sci U S A 2003, 100(24):14229-14234.

10. Paull KD, Shoemaker RH, Hodes L, Monks A, Scudiero DA, Rubinstein L, Plowman J, Boyd MR: Display and analysis of patterns of differential activity of drugs against human tumor cell lines: development of mean graph and COMPARE algorithm. J Natl Cancer Inst 1989, 81(14):1088-1092.

11. Zembutsu H, Ohnishi $Y$, Tsunoda $T$, Furukawa $Y$, Katagiri $T$, Ueyama $Y$, Tamaoki N, Nomura T, Kitahara O, Yanagawa R, Hirata K, Nakamura Y: Genome-wide cDNA microarray screening to correlate gene expression profiles with sensitivity of 85 human cancer xenografts to anticancer drugs. Cancer Res 2002, 62(2):518-527.

12. Smith V, Wirth GJ, Fiebig HH, Burger AM: Tissue microarrays of human tumor xenografts: characterization of proteins involved in migration and angiogenesis for applications in the development of targeted anticancer agents. Cancer Genomics Proteomics 2008, 5(5):263-273.

13. Harbig J, Sprinkle R, Enkemann SA: A sequence-based identification of the genes detected by probesets on the Affymetrix U133 plus 2.0 array. Nucleic Acids Res 2005, 33(3):e31.

14. Alcoser SY, Kimmel DJ, Borgel SD, Carter JP, Dougherty KM, Hollingshead MG: Real-time PCR-based assay to quantify the relative amount of human and mouse tissue present in tumor xenografts. BMC Biotechnol 2011, 11:124.

15. Shultz LD, Schweitzer PA, Christianson SW, Gott B, Schweitzer IB, Tennent B, McKenna S, Mobraaten L, Rajan TV, Greiner DL: Multiple defects in innate and adaptive immunologic function in NOD/LtSz-scid mice. J Immunol 1995, 154(1):180-191.

16. Li Q, Birkbak NJ, Gyorffy B, Szallasi Z, Eklund AC: Jetset: selecting the optimal microarray probe set to represent a gene. BMC Bioinformatics 2011, 12:474.

17. Junttila MR, Evan Gl: p53-a Jack of all trades but master of none. Nat Rev Cancer 2009, 9(11):821-829.

18. Kruse JP, Gu W: Modes of p53 regulation. Cell 2009, 137(4):609-622.

19. Stathis A, Oza A: Targeting Wee1-like protein kinase to treat cancer. Drug News Perspect 2010, 23(7):425-429.

20. Essmann F, Schulze-Osthoff $K$ : Translational approaches targeting the $\mathrm{p} 53$ pathway for anti-cancer therapy. Br J Pharmacol 2012, 165(2):328-344.

21. Ueda K, Clark DP, Chen CJ, Roninson IB, Gottesman MM, Pastan I: The human multidrug resistance (mdr1) gene. cDNA cloning and transcription initiation. J Biol Chem 1987, 262(2):505-508.

22. Johansson K, Ahlen K, Rinaldi R, Sahlander K, Siritantikorn A, Morgenstern R: Microsomal glutathione transferase 1 in anticancer drug resistance. Carcinogenesis 2007, 28(2):465-470.

23. Plowman J, Dykes DJ Jr, Hollingshead MG, Simpson-Herren L, Alley MC: Human tumor xenograft models in $\mathrm{NCl}$ drug development. In Anticancer Drug Development Guide: Preclinical Screening, Clinical Trials and Approval. Edited by Teicher BA. Totowa, NJ: Humana Press; 1997:101-125.

24. An Y, Ongkeko WM: ABCG2: the key to chemoresistance in cancer stem cells? Expert Opin Drug Metab Toxicol 2009, 5(12):1529-1542.

25. McConkey DJ, Choi W, Marquis L, Martin F, Williams MB, Shah J, Svatek R, Das A, Adam L, Kamat A, Siefker-Radtke A, Dinney C: Role of epithelialto-mesenchymal transition (EMT) in drug sensitivity and metastasis in bladder cancer. Cancer Metastasis Rev 2009, 28(3-4):335-344.

26. Dalerba P, Dylla SJ, Park IK, Liu R, Wang X, Cho RW, Hoey T, Gurney A, Huang EH, Simeone DM, Shelton AA, Parmiani G, Castelli C, Clarke MF: Phenotypic characterization of human colorectal cancer stem cells. Proc Natl Acad Sci U S A 2007, 104(24):10158-10163.
27. Kogan-Sakin I, Cohen M, Paland N, Madar S, Solomon H, Molchadsky A, Brosh R, Buganim Y, Goldfinger N, Klocker H, Schalken JA, Rotter V: Prostate stromal cells produce CXCL-1, CXCL-2, CXCL-3 and IL-8 in response to epithelia-secreted IL-1. Carcinogenesis 2009, 30(4):698-705.

28. West RB, Nuyten DS, Subramanian S, Nielsen TO, Corless CL, Rubin BP, Montgomery K, Zhu S, Patel R, Hernandez-Boussard T, Goldblum JR, Brown $P O$, van de Vijver $M$, van de Rijn M: Determination of stromal signatures in breast carcinoma. PLOS Biol 2005, 3(6):e187.

29. Baranello C, Mariani M, Andreoli M, Fanelli M, Martinelli E, Ferrandina G, Scambia G, Shahabi S, Ferlini C: Adrenomedullin in ovarian cancer: foe in vitro and friend in vivo? PLOS One 2012, 7(7):e40678.

30. Kuai WX, Wang Q, Yang XZ, Zhao Y, Yu R, Tang XJ: Interleukin-8 associates with adhesion, migration, invasion and chemosensitivity of human gastric cancer cells. World J Gastroenterol 2012, 18(9):979-985.

31. Keeley EC, Mehrad B, Strieter RM: Chemokines as mediators of tumor angiogenesis and neovascularization. Exp Cell Res 2011, 317(5):685-690.

32. Nakayama T, Hirakawa H, Shibata K, Nazneen A, Abe K, Nagayasu T, Taguchi $\mathrm{T}$ : Expression of angiopoietin-like 4 (ANGPTL4) in human colorectal cancer: ANGPTL4 promotes venous invasion and distant metastasis. Oncol Rep 2011, 25(4):929-935.

33. Creighton CJ, Bromberg-White JL, Misek DE, Monsma DJ, Brichory F, Kuick R, Giordano TJ, Gao W, Omenn GS, Webb CP, Hanash SM: Analysis of tumor-host interactions by gene expression profiling of lung adenocarcinoma xenografts identifies genes involved in tumor formation. Mol Cancer Res 2005, 3(3):119-129.

34. Nakamura T, Fidler IJ, Coombes KR: Gene expression profile of metastatic human pancreatic cancer cells depends on the organ microenvironment. Cancer Res 2007, 67(1):139-148.

35. Camphausen K, Purow B, Sproull M, Scott T, Ozawa T, Deen DF, Tofilon PJ: Influence of in vivo growth on human glioma cell line gene expression: convergent profiles under orthotopic conditions. Proc Natl Acad Sci U S A 2005, 102(23):8287-8292.

36. Stein WD, Litman T, Fojo T, Bates SE: A Serial Analysis of Gene Expression (SAGE) database analysis of chemosensitivity: comparing solid tumors with cell lines and comparing solid tumors from different tissue origins. Cancer Res 2004, 64(8):2805-2816.

37. Creighton C, Kuick R, Misek DE, Rickman DS, Brichory FM, Rouillard JM, Omenn GS, Hanash S: Profiling of pathway-specific changes in gene expression following growth of human cancer cell lines transplanted into mice. Genome Biol 2003, 4(7):R46.

38. Begley CG, Ellis LM: Drug development: raise standards for preclinical cancer research. Nature 2012, 483(7391):531-533.

39. Irizarry RA, Hobbs B, Collin F, Beazer-Barclay YD, Antonellis KJ, Scherf U, Speed TP: Exploration, normalization, and summaries of high density oligonucleotide array probe level data. Biostatistics 2003, 4(2):249-264.

doi:10.1186/1471-2164-15-393

Cite this article as: Hollingshead et al:: Gene expression profiling of 49 human tumor xenografts from in vitro culture through multiple in vivo passages - strategies for data mining in support of therapeutic studies. BMC Genomics 2014 15:393.

\section{Submit your next manuscript to BioMed Central and take full advantage of:}

- Convenient online submission

- Thorough peer review

- No space constraints or color figure charges

- Immediate publication on acceptance

- Inclusion in PubMed, CAS, Scopus and Google Scholar

- Research which is freely available for redistribution 